unit with the third is also determined by the method illustrated in figure 1.

It is apparent that a continuation of this process will yield the correct attenuation of the combination of any number of attenuators.

An extension of the process illustrated in figure 3 yields :

$$
A_{T}=\sum_{K=1}^{n} A_{T}^{K}+\sum_{l=2}^{n} 20 \log _{10}\left|1-\Gamma_{2}^{[l-1]} \Gamma_{1}^{l}\right|
$$

where,

$A_{T}^{K}=$ attenuation of $K^{\text {th }}$ network.

$\Gamma_{1}^{l}=$ reflection coefficient measured at the input terminals of the $l^{\text {th }}$ attenuator with its output terminals connected to an impedance $Z_{0}$.

$$
\begin{aligned}
\Gamma_{2}^{[l-1]}= & \text { reflection coefficient measured at the } \\
& \text { output terminals of the }[l-1]^{t h} \text { at- } \\
& \text { tenuator with the input terminals of } \\
& \text { attenuator no. } 1 \text { connected to an } \\
& \text { impedance } Z_{0} .
\end{aligned}
$$

These results may be applied to attenuators that are not used in a transmission-line system if expressions

of the form $\left(\frac{Z-Z_{0}}{Z+Z_{0}}\right)$ are substituted for the appropriate reflection coefficients and the same reference impedance $\left(Z_{0}\right)$ is used throughout.

Washington, May 23, 1950.

\title{
Total Ionization of Hydrocarbons From Mass Spectral Data
}

\author{
By Fred L. Mohler, Laura Williamson, and Helen M. Dean
}

\begin{abstract}
The total ionization is computed by adding all the mass peaks in the spectrum and multiplying by the sensitivity (current per unit pressure) for the maximum peak. This is divided by the corresponding product for $n$-butane to obtain a relative value independent of the units used. Data are taken from the API Catalog of Mass Spectral Data using revised values of sensitivity obtained by measuring pressure with a micromanometer. Total ionizations of all the isomers of a compound are nearly equal with only a few values differing greatly from the mean value. This is true in all cases where data are available for many isomers. With some exceptions total ionization increases with increasing number of carbon atoms in each series $\mathrm{C}_{n} \mathrm{H}_{2 \mathrm{n}+2}, \mathrm{C}_{\mathrm{n}} \mathrm{H}_{2 \mathrm{n}}$, etc. Total ionization tends to decrease in compounds with the same number of carbon atoms and decreasing number of hydrogen atoms but there are many exceptions. Tables summarize data for 198 hydrocarbons.

Values of total ionization of isomers will in some cases permit computing all isomers as a group in chemical analysis without identifying the compounds.
\end{abstract}

\section{Introduction}

Tables of mass spectra [1] ${ }^{1}$ commonly give the intensity of mass peaks relative to the maximum peak taken as 100 and the sensitivity (current per unit pressure in the gas reservoir) for the maximum peak in arbitrary units. The tables also give the sensitivity for the maximum peak of $n$-butane at mass 43 in the same units. The ratio of the sensitivity of any compound to that of $n$-butane is a number that is independent of the arbitrary units of current and rate of leak from the gas reservoir to the ionization chamber. The sum of all the mass peaks times the sensitivity for the maximum peak is a number proportional to the total ionization for the compound, and the ratio of this to the total ionization of $n$-butane is again a number independent of the arbitrary units. These relative values will depend to some extent on instrumental selectivity and will differ somewhat for different types of instruments. In the Consolidated mass spectrometer the spectrum is covered by varying the ion accelerating voltage with constant magnetic field, and heavy ions are collected with less efficiency than light ions. This

1 Figures in brackets indicate the literature references at the end of this paper. introduces a small but unknown uncertainty in deriving total ionization by adding the mass peaks.

A greater source of error in published data comes from the determination of the sensitivity or current per unit pressure in the gas reservoirs. The common procedure for measuring this pressure has been to admit the gas into a volume of about 2 cubic centimeters and measure the pressure of 10 to 40 millimeters on a mercury manometer. Then the gas is expanded a thousandfold to give a pressure of 10 to 40 microns in the reservoir. The gas pipet method leads to very large errors when the vapor pressure is nearly equal to the manometer pressure and the estimated pressure will be much too high. Dibeler, Cordero, and Greenough [2, 3] have developed a micromanometer suitable for measuring directly the pressure in the gas reservoir. The pressure-sensitive element is a thin metal diaphragm and the motion of the diaphragm is measured electrically by the change in mutual induction between two coils close to the diaphragm.

Comparative measurements with the gas pipet and with the micromanometer show that use of the gas pipet leads to large experimental errors for all hydrocarbons with eight or more carbon atoms. For this reason all tables of mass spectra published by 
this Bureau in the API catalog since February 1949 give sensitivities based on micromanometer readings, and sensitivities have been redetermined for nearly all the heavier hydrocarbon spectra published before this date. A table of revised values relative to $n$-butane has been published in the API Catalog of Mass Spectral Data [1].

When the total ionization is recomputed on the basis of the corrected values of the sensitivity relative to $n$-butane, some regularities are found that were previously concealed by experimental errors in estimating the pressure. This paper gives a summary of results.

\section{Computation of Total Ionization}

In nearly all cases we have used the data at 50 volts ionizing voltage published in the API catalog. All the mass peaks are added and multiplied by the sensitivity for the base peak, and this product is divided by the similar product for $n$-butane. As noted above there is some error introduced because the Consolidated mass spectrometer is slightly less sensitive to heavy ions than to light ions. This is partly compensated for by the fact that larger magnetic fields are used to cover the spectra of heavier compounds. Thus, hydrocarbons with less than six carbon atoms including $n$-butane are measured with a magnetic field requiring 865 volts ion accelerating voltage to focus ions of mass 43. Hydrocarbons with six to eight carbon atoms are measured with a field requiring 1,130 volts for mass 43 , and the sensitivity is increased by a factor 1.06. For hydrocarbons with nine or more carbon atoms the field is 1,700 volts for mass 43 and the sensitivity 1.08 times that at 865 volts. This effect could easily be corrected, but it compensates at least in part for the fact that the average mass of the ions of a heavy hydrocarbon is in general greater than the average mass of $n$-butane ions. The tables give values relative to $n$-butane measured with 865 volts ion accelerating voltage for mass 43 .

Results of independent measurements of sensitivity relative to $n$-butane are reproducible to within about 2 percent. Larger errors seem to arise over long periods of time or when ionization chambers are changed. Possibly this is because the efficiency of collecting ions depends rather critically on focusing fields and slit widths and on the initial kinetic energy of the ions.

\section{Results}

Table 1 gives the sum of the mass peaks, the sensitivity, and the total ionization relative to $n$-butane for the eighteen $\mathrm{C}_{8} \mathrm{H}_{18}$ isomers. A previous publication of this laboratory [4] gives a similar table but with sensitivity measured by the gas pipet. Values of the sensitivity derived in reference [4] are much higher than those given in table 1 by factors ranging from 1.7 to 1.07 . This gives a serious error in the total ionization reported in [4] and completely conceals a regularity shown in table 1 . Whereas the sum of the mass peaks and sensitivities cover a
TABle 1. Sensitivity and total ionization relative to $n$-butane for octane mass spectra

\begin{tabular}{|c|c|c|c|c|}
\hline Compound & $\begin{array}{l}\text { Maxi- } \\
\text { mum } \\
\text { peak }\end{array}$ & $\begin{array}{c}\text { Sum of } \\
\text { mass } \\
\text { peaks }\end{array}$ & $\begin{array}{l}\text { Sensitivity } \\
\text { relative to } \\
n \text {-butane }\end{array}$ & $\begin{array}{l}\text { Total ioni- } \\
\text { zation rela- } \\
\text { tive to } n \text { - } \\
\text { butane }\end{array}$ \\
\hline$n$-Octane & 43 & 397 & 1. 44 & 1.83 \\
\hline 2-Methylheptane. & 43 & 422 & 1. 30 & 1.75 \\
\hline 3-Methylheptane & 43 & 472 & 1. 21 & 1.83 \\
\hline 4-Methylheptane & 43 & 363 & 1. 67 & 1. 94 \\
\hline 2,2-Dimethylhexane & 57 & 242 & 2. 41 & 1.87 \\
\hline 2,3-Dimethylhexane. & 43 & 370 & 1. 52 & 1. 80 \\
\hline 2,4-Dimethylhex & 43 & 455 & 1. 29 & 1.88 \\
\hline 2,5-Dimethylhexane.. & 43 & 416 & 1. 35 & 1. 80 \\
\hline 3,3-Dimethy!hex & 43 & 390 & 1. 43 & 1. 78 \\
\hline 3,4-Dimethylhexane.. & 56 & 488 & 1. 14 & 1.78 \\
\hline 3-Ethylhexane_ & 43 & 309 & 1. 89 & 1. 87 \\
\hline $2,2,3$-Tri & 57 & 292 & 1.86 & 1.74 \\
\hline 2,2,4-Trimethylp & 57 & 249 & 2.33 & 1.86 \\
\hline 2,3,3-Trir & 43 & 374 & 1. 41 & 1. 69 \\
\hline $2,3,4$-Trimethylpe & 43 & 337 & 1. 56 & 1. 68 \\
\hline 2-Methyl-3-ethy & 43 & 348 & 1. 61 & 1. 79 \\
\hline 3-Methyl-3-eth & 43 & 326 & 1.68 & 1.75 \\
\hline 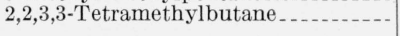 & 57 & 237 & 2. 12 & 1. 61 \\
\hline Mean & & & & $1.79 \pm 0.06$ \\
\hline
\end{tabular}

nearly two-fold range of values, the total ionization relative to $n$-butane is nearly constant. Most of the octanes give values of total ionization that are equal within experimental error, but four or five values differ from the mean by more than the expected error. This variation cannot be ascribed to instrumental selectivity for ions that differ in mass, since four of the compounds that have nearly identical spectra give total ionizations that differ considerably. These are 2,2-dimethyl-hexane; $2,2,3$ trimethylpentane; 2,2,4-trimethylpentane; and 2,2,3,3-tetramethylbutane. For these compounds the total ionization ranges from 1.87 to 1.61 .

Table 2 summarizes values of total ionization for a large number of compounds. Column 1 gives the empirical chemical formula, column 2 gives the number of isomers measured, and column 3 gives the mean value of the total ionization relative to $n$ butane and the mean deviation from the mean value. In every case where a large number of isomers has been measured one can make the same generalization as was made for the 18 octanes. The values of the total ionization are nearly equal and most, but not all, of the values are equal within the expected experimental errors.

Compounds in table 2 have been grouped according to the empirical formulae, and the first twelve compounds are the paraffins of formula $\mathrm{C}_{\mathrm{n}} \mathrm{H}_{2 \mathrm{n}+2}$. Total ionization for all isomers has been computed for compounds with less than ten carbon atoms and only the normal compounds are given for compounds with 10 , 11, and 12 carbon atoms. For compounds with six or less carbon atoms the sensitivity was measured with the gas pipet, and a few check measurements indicate that there is no serious error. Heptanes give appreciably higher values of sensitivity by this method. Data for the 35 nonanes corresponding to table 1 have been published in a paper on "Mass spectra of the nonanes" [5]. These values have been computed from data for 70 volts ionizing voltage. The total ionization at 70 volts is slightly greater than at 50 volts in all compounds, but there seems to be 
TABLE 2. Total ionization relative to $n$-butane

\begin{tabular}{|c|c|c|c|c|c|}
\hline Formula & $\begin{array}{l}\text { Number } \\
\text { of isomers }\end{array}$ & $\begin{array}{l}\text { Total ioni- } \\
\text { zation }\end{array}$ & Formula & $\begin{array}{c}\text { Number } \\
\text { of isomers }\end{array}$ & $\begin{array}{l}\text { Total ioni- } \\
\text { zation }\end{array}$ \\
\hline $\mathrm{CH}_{4-.}$ & 1 & 0.46 & & & \\
\hline $\mathrm{C}_{2} \mathrm{H}_{6}$ & 1 & .70 & $\mathrm{C}_{2} \mathrm{H}_{4-}$ & 1 & 0.56 \\
\hline $\mathrm{C}_{3} \mathrm{H}_{8}-$ & 1 & .87 & $\mathrm{C}_{3} \mathrm{H}_{6}$ & 2 & $.75 \pm 0.06$ \\
\hline $\mathrm{C}_{4} \mathrm{H}_{10}$ & 2 & $.98 \pm 0.02$ & $\mathrm{C}_{4} \mathrm{H}_{8}$ & 5 & $.86 \pm 0.02$ \\
\hline $\mathrm{C}_{5} \mathrm{H}_{12}$ & 3 & 1. $09 \pm 0.07$ & $\mathrm{C}_{5} \mathrm{H}_{10}$. & 7 & $1.03 \pm 0.03$ \\
\hline $\mathrm{C}_{6} \mathrm{H}_{14-}$ & 5 & 1. $54 \pm 0.06$ & $\mathrm{C}_{6} \mathrm{H}_{12 \ldots} \ldots$ & 20 & $1.42 \pm 0.06$ \\
\hline $\mathrm{C}_{7} \mathrm{H}_{16--}$ & 9 & 1. $69 \pm 0.05$ & & & \\
\hline $\mathrm{C}_{8} \mathrm{H}_{18}$ & 18 & 1. $79 \pm 0.06$ & $\mathrm{C}_{8} \mathrm{H}_{16-}$ & 22 & $1.58 \pm 0.07$ \\
\hline $\mathrm{C}_{9} \mathrm{H}_{20}$ & 35 & 1. $94 \pm 0.13$ & $\mathrm{C}_{9} \mathrm{H}_{18} \ldots$ & 6 & $1.91 \pm 0.09$ \\
\hline $\mathrm{n}-\mathrm{C}_{10} \mathrm{H}_{22} \ldots$ & 1 & 1. 80 & $\mathrm{n}-1-\mathrm{C}_{10} \mathrm{H}_{20}-$ & 1 & 2. 27 \\
\hline $\mathrm{n}-\mathrm{C}_{11} \mathrm{H}_{24} \ldots$ & 1 & 1. 98 & $\mathrm{n}-1-\mathrm{C}_{11} \mathrm{H}_{22}-$ & 1 & 2. 06 \\
\hline $\mathrm{n}-\mathrm{C}_{12} \mathrm{H}_{26} \ldots$ & 1 & 1. 94 & & & \\
\hline $\mathrm{C}_{2} \mathrm{H}_{2-}$ & 1 & 0.55 & & & \\
\hline $\mathrm{C}_{3} \mathrm{H}_{4} \ldots$ & $\begin{array}{l}1 \\
4\end{array}$ & & & & \\
\hline $\begin{array}{l}\mathrm{C}_{4} \mathrm{H}_{6} \ldots \\
\mathrm{C}_{5} \mathrm{H}_{8}\end{array}$ & $\begin{array}{r}4 \\
11\end{array}$ & $.87 \pm 0.07$ & $\mathrm{C}_{4} \mathrm{H}_{4--}$ & 1 & 0.43 \\
\hline $\mathrm{C}_{6} \mathrm{H}_{10}$ & 7 & $\begin{array}{l}1.03 \pm 0.04 \\
1.26 \pm 0.09\end{array}$ & $\mathrm{C}_{6} \mathrm{H}_{8}$ & 1 & 1.06 \\
\hline $\mathrm{C}_{8} \mathrm{H}_{14---}$ & 2 & 1. $67 \pm 0.04$ & $\mathrm{C}_{8} \mathrm{H}_{12-}$ & 1 & 1.34 \\
\hline $\mathrm{C}_{10} \mathrm{H}_{18--}$ & 2 & 1. $64 \pm 0.22$ & $\mathrm{C}_{10} \mathrm{H}_{16 \ldots}$ & 2 & 1. $61 \pm 0.01$ \\
\hline $\mathrm{C}_{4} \mathrm{H}_{2--}$ & 1 & 0.69 & & & \\
\hline $\mathrm{C}_{6} \mathrm{H}_{6-}$ & 2 & 1. $10 \neq 0.04$ & & & \\
\hline $\mathrm{C}_{7} \mathrm{H}_{8} \ldots$ & 1 & 1. 13 & & & \\
\hline $\mathrm{C}_{8} \mathrm{H}_{10}$ & $\begin{array}{l}4 \\
8\end{array}$ & 1. $15 \pm 0.06$ & $\mathrm{C}_{8} \mathrm{H}_{8 \ldots-}$ & 1 & 1. 18 \\
\hline $\begin{array}{l}\mathrm{C}_{9} \mathrm{H}_{1} \\
\mathrm{C}_{10} \mathrm{H}\end{array}$ & $\begin{array}{l}8 \\
4\end{array}$ & 1. $27 \pm 0.07$ & & & \\
\hline $\mathrm{C}_{10} \mathrm{H}_{14 \ldots}$ & 4 & 1. $17 \pm 0.05$ & & & \\
\hline $\mathrm{C}_{10} \mathrm{H}_{8} \ldots$ & 1 & 1. 45 & & & \\
\hline
\end{tabular}

little if any difference in the value of the ratio to $n$ butane. The mean error and the extreme departures from the mean are somewhat greater than for the octanes. Eight nonanes with nearly identical spectra show nearly the full range of values for total ionization, so again there is no evidence that variation in total ionization is caused by instrumental selectivity. Experimental errors may be somewhat greater here as the spectra were measured over a long period of time. Values of total ionization increase progressively with increasing number of carbon atoms up to $\mathrm{C}_{10} \mathrm{H}_{22}$.

Values for total ionization of compounds of formula $\mathrm{C}_{\mathrm{n}} \mathrm{H}_{2 \mathrm{n}}$ are given in the same row as the paraffins with the same value of $\mathrm{n}$. These compounds include olefins and cycloparaffins. $\mathrm{C}_{3} \mathrm{H}_{6}$ includes propene, 0.69 , and cyclopropane, $0.80 . \quad \mathrm{C}_{4} \mathrm{H}_{8}$ includes four butenes of mean total ionization, 0.87 , and cyclobutane, 0.83 . The $\mathrm{C}_{5}$ compounds are six pentenes, 1.02, and cyclopentane, 1.07. $\mathrm{C}_{6} \mathrm{H}_{12}$ includes 16 hexenes and six cycloparaffins with mean values of 1.43 and 1.40 , respectively. $\mathrm{C}_{7} \mathrm{H}_{14}$ isomers have been omitted as most of the sensitivity values have not been based on micromanometer pressure measurements and data are considered inaccurate. $\mathrm{C}_{8} \mathrm{H}_{16}$ includes four olefins and 18 cycloparaffins giving values of 1.63 and 1.57. Mean values for six $\mathrm{C}_{9}$ cycloparaffins and for 1-decene and 1-undecene are given. In general, differences between cyclics and olefins are no greater than the differences found among isomers of the same chemical class. Except for the two heaviest compounds, $\mathrm{C}_{\mathrm{n}} \mathrm{F}_{2 \mathrm{n}}$ compounds give values of total ionization slightly less than the corresponding paraffins.

The $\mathrm{C}_{\mathrm{n}} \mathrm{H}_{2 \mathrm{n}-2}$ compounds include a variety of chemical classes. $\mathrm{C}_{2} \mathrm{H}_{2}$ is acetylene, $\mathrm{C}_{3} \mathrm{H}_{4}$ methylacetylene, and $\mathrm{C}_{4} \mathrm{H}_{6}$ includes butadienes and butynes. The eleven $\mathrm{C}_{5} \mathrm{H}_{8}$ isomers include a variety of chemical compounds that differ strikingly in their spectra and the equality of the total ionization is very significant [6]. There is more variation in total ionization among the $\mathrm{C}_{6} \mathrm{H}_{10}$ isomers. $\mathrm{C}_{8} \mathrm{H}_{14}$ includes 1-octyne and 2,5-dimethyl-1,5-hexadiene. The two $\mathrm{C}_{10} \mathrm{H}_{18}$ compounds are cis- and trans-decahydronaphthalene. The total ionization values are 1.42 and 1.85 , respectively, which is an exceptionally large difference for two isomers. Values for total ionization of $\mathrm{C}_{n} \mathrm{H}_{2 \mathrm{n}-2}$ compounds are sometimes greater and sometimes less than the $\mathrm{C}_{n} \mathrm{H}_{2 \mathrm{n}}$ compounds with the same value of $\mathrm{n}$.

Only five examples of $\mathrm{C}_{\mathrm{n}} \mathrm{H}_{2 \mathrm{n}-4}$ compounds have been studied. $\mathrm{C}_{4} \mathrm{H}_{4}$ is 1-buten-3-yne from a spectrum published by Humble Oil and Refining Co. [7], $\mathrm{C}_{6} \mathrm{H}_{8}$ is cyclohexadiene, and $\mathrm{C}_{8} \mathrm{H}_{12}$ is vinylcyclohexene. Two terpenes, $\mathrm{C}_{10} \mathrm{H}_{16}$, are alpha pinene and tricyclene, and the total ionization of these is identical within experimental error. These chemically different compounds are in this respect in marked contrast to the two decahydronaphthalenes $\left(\mathrm{C}_{10} \mathrm{H}_{18}\right)$, which are structurally similar although they show a large difference in total ionization.

$\mathrm{C}_{\mathrm{n}} \mathrm{H}_{2 \mathrm{n}-6}$ compounds are alkylbenzenes with two exceptions. $\mathrm{C}_{4} \mathrm{H}_{2}$ is butadiyne computed from data published by Union Oil Co. [8]. The $\mathrm{C}_{6} \mathrm{H}_{6}$ isomers include benzene and 2,4-hexadiyne. The two compounds are chemically very different but the mass spectra and the total ionization are similar. The $\mathrm{C}_{\mathrm{n}} \mathrm{H}_{2 \mathrm{n}-6}$ compounds give less total ionization than compounds with more hydrogen atoms with one or two exceptions.

There is only one measurement for a compound $\mathrm{C}_{\mathrm{n}} \mathrm{H}_{2 \mathrm{n}-8}$, namely styrene. The total ionization falls in the same range of values as found for the $\mathrm{C}_{8}$ alkylbenzenes.

Naphthalene is an example of a compound of formula $\mathrm{C}_{\mathrm{n}} \mathrm{H}_{2 \mathrm{n}-12}$. The total ionization is greater than that of $\mathrm{C}_{10}$ alkylbenzenes and comparable with the decahydronaphthalenes of formula $\mathrm{C}_{n} \mathrm{H}_{2 \mathrm{n}-2}$.

The only striking generalization concerning total ionization is that the total ionization of isomers is nearly equal. Wherever there are many isomers this relation is shown conclusively, but individual compounds occasionally differ from the mean value by much more than the experimental error. The total ionization tends to increase with increasing number of carbon atoms within the same series up to $\mathrm{C}_{10}$. It tends to decrease with decreasing number of hydrogen atoms and equal number of $\mathrm{C}$ atoms but there are many exceptions.

It is of interest to consider structurally related compounds instead of all the isomers, and table 3 gives values for the normal paraffins, the normal olefins with a double bond in the first position, and some normal acetylenes with a triple bond in the first position. The values for the normal compounds do not differ systematically from the average for all isomers, and the trend of values with increasing number of carbon atoms and decreasing number of $\mathrm{H}$ atoms shows the same type of irregularities that were noted for average values. It was noted above that cyclics and olefins of the same molecular weight show no systematic difference in total ionization. 
The irregularities are not of a type to be explained by instrumental selectivity arising from the fact that heavy ions are collected with somewhat less efficiency than light ions.

TABLE 3. Total ionization relative to $n$-butane

\begin{tabular}{|c|c|c|c|c|c|}
\hline $\begin{array}{l}\text { Normal } \\
\text { paraffins }\end{array}$ & $\begin{array}{c}\text { Total } \\
\text { ionization }\end{array}$ & $\begin{array}{c}\text { Normal } \\
\text { 1-olefines }\end{array}$ & $\begin{array}{c}\text { Total } \\
\text { ionization }\end{array}$ & $\begin{array}{c}\text { Normal } \\
\text { 1-acetylenes }\end{array}$ & $\begin{array}{c}\text { Total } \\
\text { ionization }\end{array}$ \\
\hline $\begin{array}{l}\mathrm{CH}_{4} \\
\mathrm{C}_{2} \mathrm{H}_{6} \\
\mathrm{C}_{3} \mathrm{H}_{8} \\
\mathrm{C}_{4} \mathrm{H}_{10} \\
\mathrm{C}_{5} \mathrm{H}_{12} \\
\mathrm{C}_{6} \mathrm{H}_{14} \\
\mathrm{C}_{7} \mathrm{H}_{16} \\
\mathrm{C}_{8} \mathrm{H}_{18} \\
\mathrm{C}_{9} \mathrm{H}_{20} \\
\mathrm{C}_{10} \mathrm{H}_{22} \\
\mathrm{C}_{11} \mathrm{H}_{24} \\
\mathrm{C}_{12} \mathrm{H}_{26}\end{array}$ & $\begin{array}{r}0.46 \\
.70 \\
.87 \\
1.00 \\
1.17 \\
1.55 \\
1.64 \\
1.83 \\
1.98 \\
1.80 \\
1.98 \\
1.94\end{array}$ & $\begin{array}{l}\mathrm{C}_{2} \mathrm{H}_{4} \\
\mathrm{C}_{3} \mathrm{H}_{6} \\
\mathrm{C}_{4} \mathrm{H}_{8} \\
\mathrm{C}_{5} \mathrm{H}_{10} \\
\mathrm{C}_{6} \mathrm{H}_{12} \\
\mathrm{C}_{8} \mathrm{H}_{16} \\
\mathrm{C}_{9} \mathrm{H}_{18} \\
\mathrm{C}_{10} \mathrm{H}_{20} \\
\mathrm{C}_{11} \mathrm{H}_{22}\end{array}$ & $\begin{array}{r}0.56 \\
.69 \\
.87 \\
1.05 \\
1.49 \\
1.79 \\
2.13 \\
2.27 \\
2.06\end{array}$ & $\begin{array}{l}\mathrm{C}_{2} \mathrm{H}_{2} \\
\mathrm{C}_{3} \mathrm{H}_{4} \\
\mathrm{C}_{4} \mathrm{H}_{6} \\
\mathrm{C}_{5} \mathrm{H}_{8} \\
\mathrm{C}_{6} \mathrm{H}_{10} \\
\mathrm{C}_{8} \mathrm{H}_{14}\end{array}$ & $\begin{array}{r}0.55 \\
.87 \\
.83 \\
1.06 \\
1.29 \\
1.64\end{array}$ \\
\hline
\end{tabular}

The fact that isomers give nearly the same total ionization can be applied to analysis of complicated mixtures when it is impossible to determine the separate components. Thus, one could analyze for a trace of gasoline vapor in air on the basis of the sum of all the peaks and an estimate as to the average number of carbon atoms in the mixture. If, for instance, the spectrum indicated that heptanes were predominant, the sensitivity factor would be, from table $2,1.69 \times 312 \times$ sensitivity of $n$-butane where 312 is the sum of the peaks in the $n$-butane spectrum. This is a better approximation than is obtained by using the sensitivity of any one compound in cases where one may reasonably expect that a mixture of compounds is present. We are indebted to $\mathrm{S}$. Schuhmann of this Bureau for calling attention to the possibility of analyzing for all isomers as a group.

\section{References}

[1] Catalog of Mass Spectral Data, American Petroleum Institute, Research Project 44.

[2] V. H. Dibeler and F. Cordero, J. Research NBS, publication pending.

[3] M. L. Greenough and W. F. Williams, J. Research NBS, publication pending.

[4] E. G. Bloom, F. L. Mohler, J. H. Lengel, and C. E. Wise, J. Research NBS 41, 129 (1948).

[5] F. L. Mohler, L. M. Williamson, C. E. Wise, E. J. Wells, H. M. Dean, and E. G. Bloom, J. Research NBS, in press.

[6] F. L. Mohler, E. G. Bloom, L. M. Williamson, C. E. Wise, and E. J. Wells, J. Research NBS 43, 533 (1949)

[7] API Catalog of Mass Spectral Data, Serial No. 423.

[8] API Catalog of Mass Spectral Data, Serial No. 74

Washington, May 18, 1950. 